\title{
Replacement of the aortic root for acute prosthetic valve endocarditis: Prosthetic composite versus aortic allograft root replacement
}

\author{
Rainer G. Leyh, MD, PhD \\ Karsten Knobloch, MD \\ Christian Hagl, MD \\ Arjang Ruhparwar, MD \\ Stefan Fischer, MD, MSc \\ Theo Kofidis, MD \\ Axel Haverich, MD, PhD
}

From the Division of Thoracic and Cardiovascular Surgery, Hannover Medical School, Hannover, Germany.

Received for publication June 15, 2003; revisions received July 30, 2003; accepted for publication Aug 21, 2003.

Address for reprints: Rainer G. Leyh, MD, $\mathrm{PhD}$, Division of Thoracic and Cardiovascular Surgery, Hannover Medical School, Carl Neuberg St. 1, 30623 Hannover, Germany (E-mail: leyh@thg.mh-hannover.de).

J Thorac Cardiovasc Surg 2004;127:1416-20

$0022-5223 / \$ 30.00$

Copyright () 2004 by The American Association for Thoracic Surgery

doi:10.1016/j.jtcvs.2003.08.047
Objective: Aortic root replacement for prosthetic aortic valve endocarditis with accompanying destruction of the aortic root is a well-established surgical intervention. However, there is still no consensus whether prosthetic material or allogeneic material should be used. Here we report on our experience with prosthetic composite and aortic allograft root replacement in such patients during a 10-year interval.

Methods: From 1991 through 2001, 29 patients with prosthetic aortic valve endocarditis combined with aortic root destruction underwent reoperation at our institution. Sixteen patients received aortic root replacement with a cryopreserved aortic root allograft (group A) and 13 with a prosthetic composite graft (group B). The interval between the initial operation and reoperation was 29 months (range, 5-168 months) in group A and 55 months (range, 7-248 months) in group B.

Results: Hospital mortality was $18.5 \%(\mathrm{n}=5$ patients, 3 in group A and 2 in group B). Median follow-up was 21 months (range, 1-48 months) for group A and 34 months (range, $1-152$ months) for group B $(P>.2)$. Survival at 1 and 5 years was $81 \% \pm 10 \%$ and $81 \% \pm 10 \%$ in group A and $85 \% \pm 10 \%$ and $85 \% \pm 10 \%$ in group $\mathrm{B}$, respectively. No patient underwent reoperation for recurrent prosthetic aortic valve endocarditis.

Conclusions: Our results indicate that excellent long-term results can be achieved regardless of the material used for aortic root replacement in patients with prosthetic aortic valve endocarditis.

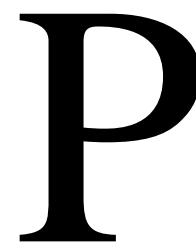
rosthetic valve endocarditis (PVE) is an important complication after aortic valve replacement. Blumberg and associates ${ }^{1}$ described infectious destruction of the aortic root in $56 \%$ to $100 \%$ of these patients. The associated hospital mortality for these patients can reach as high as $30 \% .^{2-4}$ Thorough debridement of infected prosthetic material and infected tissue, re-replacement of the entire aortic root, and prolonged antibiotic therapy are all accepted strategies for the treatment of PVE. ${ }^{5-10}$ However, there is still debate whether to use biologic material (homograft, autograft, or xenograft) or prosthetic material in these patients., ${ }^{2,5,6,8-16}$

In this retrospective study we reviewed the clinical data and outcomes for 29 patients who underwent reoperation for PVE associated with infectious destruction of the aortic root with homograft or composite aortic root replacement from 1991 through 2001 to elucidate whether the material used for aortic root replacement in PVE has any influence on short-term and long-term outcome. 
TABLE 1. Patient data and preoperative complications

\begin{tabular}{|c|c|c|c|}
\hline Characteristic & $\begin{array}{l}\text { Group } A \\
(n=16)\end{array}$ & $\begin{array}{l}\text { Group B } \\
(n=13)\end{array}$ & $\begin{array}{c}P \\
\text { value }\end{array}$ \\
\hline Men (n [\%]) & $13(81.2 \%)$ & $10(76.9 \%)$ & $>.2$ \\
\hline Mean age $(y)^{*}$ & $61(37-72)$ & $48(23-81)$ & $>.2$ \\
\hline Mean follow-up $(\mathrm{mo})^{*}$ & $21(1-48)$ & $34(1-152)$ & $>.2$ \\
\hline $\begin{array}{l}\text { Time between initial } \\
\text { operation and } \\
\text { reoperation }(\mathrm{mo})^{*}\end{array}$ & $29(5-168)$ & $55(7-248)$ & .54 \\
\hline $\begin{array}{l}\text { Mean preoperative NYHA } \\
\text { functional class }\end{array}$ & $3.7 \pm 0.49$ & $3.8 \pm 0.45$ & $>.2$ \\
\hline $\begin{array}{l}\text { Cardiogenic shock (n } \\
{[\%] \text { ) }}\end{array}$ & $2(12.5 \%)$ & $2(15.3 \%)$ & $>.2$ \\
\hline Septic (n [\%]) & $7(43.8 \%)$ & $6(46.1 \%)$ & $>.2$ \\
\hline Septic embolism (n [\%]) & $2(12.5 \%)$ & $1(7.7 \%)$ & $>.2$ \\
\hline $\begin{array}{l}\text { Acute renal failure (n } \\
{[\%] \text { ) }}\end{array}$ & $3(18.8 \%)$ & $2(15.3 \%)$ & $>.2$ \\
\hline $\begin{array}{l}\text { Preoperative artificial } \\
\text { ventilation (n [\%]) }\end{array}$ & $3(18.8 \%)$ & $3(23.1 \%)$ & $>.2$ \\
\hline
\end{tabular}

NYHA, New York Heart Association.

*Data are expressed expressed as medians with ranges. Note that some patients had more than one preoperative complication.

\section{Material and Methods}

In a 10-year period between 1991 and 2001, 29 patients underwent reoperation for PVE with infectious destruction of the aortic root after aortic valve or composite replacement in our institution (6 women and 23 men; mean age, $51 \pm 14$ years; range, 23-81 years). According to the surgeon's preference, either homograft aortic root replacement (group $\mathrm{A}, \mathrm{n}=16$ ) or composite aortic root replacement (group $\mathrm{B}, \mathrm{n}=13$ ) was performed. All patients were in New York Heart Association functional class III and IV preoperatively. Nine patients had severe preoperative complications, such as cardiogenic shock. Patient data, including information on the preoperative complications, are depicted in Table 1.

Sepsis was defined as a temperature of greater than $38^{\circ} \mathrm{C}$, increased cardiac output, low systemic vascular resistance, and low oxygen extraction ratio. Acute renal failure was defined as a rapid decrease of glomerular filtration, with a subsequent progressive increase of serum creatinine, blood urea nitrogen, and electrolyte imbalance and the development of metabolic acidosis accompanied by oliguria ( $<500 \mathrm{~mL}$ of urine output in 24 hours) or anuria. Low cardiac output was defined as a mean arterial pressure of less than $60 \mathrm{~mm} \mathrm{Hg}$ in the presence of a cardiac index of less than $2 \mathrm{~L} \cdot \min ^{-1} \cdot \mathrm{m}^{-2}$, with a mean right atrial pressure of $18 \mathrm{~mm}$ $\mathrm{Hg}$ or greater and a mean left atrial pressure of $18 \mathrm{~mm} \mathrm{Hg}$ or greater.

\section{Detected Infectious Microorganisms Causing PVE}

PVE was caused mainly by Staphylococcus aureus $(\mathrm{n}=12$ [41\%]), and in $6(21 \%)$ patients the infectious microorganism could not be detected (Table 2).

\section{Surgical Technique}

Operations were performed with moderate hypothermia in 24 $(83 \%)$ patients. However, in $5(17 \%)$ patients deep hypothermia was chosen for aortic arch surgery. For myocardial protection,
TABLE 2. Organism cultured from blood or intraoperative specimen

\begin{tabular}{lllc}
\hline Organism & $\begin{array}{l}\text { Group A } \\
\text { (n= 16) }\end{array}$ & $\begin{array}{l}\text { Group B } \\
\text { (n= 13) }\end{array}$ & P value \\
\hline Enterococcus faecalis (n [\%]) & $4(25 \%)$ & $4(30.8 \%)$ & $>.2$ \\
Staphylococcus aureus (n [\%]) & $6(37.5 \%)$ & $6(46.1 \%)$ & $>.2$ \\
Candida albicans (n [\%]) & $2(12.5 \%)$ & $1(7.7 \%)$ & $>.2$ \\
Not known (n [\%]) & $4(25 \%)$ & $2(15.3 \%)$ & $>.2$ \\
\hline
\end{tabular}

either cold crystalloid cardioplegia or cold blood cardioplegia was used. The infected prosthetic aortic valves or composite grafts were completely excised. Abscess cavities were opened, curetted, washed out with iodine solution, and filled with a gentamicinsaturated fibrin glue, as described by Karck and coworkers. ${ }^{17}$ Macroscopically infected or necrotic tissue was widely resected, regardless of the proximity of the conduction system. Reconstruction of the aortic annulus with autologous pericardium or glutaraldehyde-fixed bovine pericardium was performed in 4 patients (group $\mathrm{A}, \mathrm{n}=1$; group $\mathrm{B}, \mathrm{n}=3$ ). Homograft implantation into the aortic root was carried out with interrupted monofilament suture material (4-0 Prolene, Ethicon). Mechanical composite grafts (St Jude Medical, $\mathrm{n}=3$; Carbomedics $\mathrm{n}=9$; ATS, $\mathrm{n}=1$ ) were implanted with single Teflon-armed sutures. Coronary buttons were reimplanted with a continuous monofilament suture (5-0 Prolene, Ethicon). The distal anastomosis was carried out with a continuous monofilament suture (4-0 or 3-0 Prolene, Ethicon). Valve prostheses, Dacron prostheses, and Teflon patches were incubated in gentamicin solution before implantation for $5 \mathrm{~min}$ utes.

In addition, the sewing ring of the prosthesis was irrigated with a mixture of fibrin glue and gentamicin before implantation. In 12 $(41 \%)$ patients additional surgical procedures were performed, as depicted in Table 3.

\section{Postoperative Antibiotic Therapy}

Patients received antibiotic therapy specifically directed against the detected microorganisms. If the microorganism could not be isolated, broad-spectrum antibiotic therapy was administered (vancomycin and broad-spectrum gram-negative coverage). In all patients intravenous antibiotic therapy was maintained for 6 weeks postoperatively.

\section{Statistical Analysis}

Data are expressed as medians with ranges or as the mean \pm SD where appropriate. Demographic and baseline variables were analyzed by using the Student $t$ test for continuous variables and the Fisher exact test for qualitative variables. Analysis of survival was performed by using the Kaplan-Meier method. Statistical differences in Kaplan-Meier survival estimates were determined by using the log-rank test. Statistical analyses were performed by using the SPSS for Windows software package (SPSS Inc).

\section{Results}

Five (18.5\%) patients died during the hospital stay, 3 $(18.7 \%)$ in group A and $2(15.3 \%)$ in group B. One patient 
TABLE 3. Intraoperative data

\begin{tabular}{lccc}
\hline & $\begin{array}{c}\text { Group A } \\
(\mathbf{n}=\mathbf{1 6})\end{array}$ & $\begin{array}{c}\text { Group B } \\
(\mathbf{n}=\mathbf{1 3})\end{array}$ & $\boldsymbol{P}$ value \\
\hline CPB time (min) & $203(149-363)$ & $172(85-268)$ & .047 \\
Crossclamp time (min)* & $132(97-177)$ & $107(54-127)$ & .034 \\
$\begin{array}{l}\text { Circulatory arrest (n } \\
\quad[\%])\end{array}$ & $3(18.7 \%)$ & $2(15.4 \%)$ & $>.2$ \\
$\begin{array}{l}\text { Concomitant procedure } \\
\quad \text { MVS (n [\%]) }\end{array}$ & $2(12.5 \%)$ & $1(7.7 \%)$ & $>.2$ \\
$\quad \begin{array}{l}\text { Aortic arch } \\
\text { replacement (n [\%]) }\end{array}$ & $2(12.5 \%)$ & $2(15.4 \%)$ & $>.2$ \\
$\quad$ CABG (n [\%]) & $3(18.7 \%)$ & $1(7.7 \%)$ & .04 \\
\hline
\end{tabular}

$\overline{C P B}$, Cardiopulmonary bypass; $M V S$, mitral valve surgery; $C A B G$, coronary artery bypass grafting.

*Data are expressed expressed as medians with ranges.

in group A died in the operating room as a result of therapyrefractory low cardiac output syndrome. Two patients in each group died of cardiac causes or multiorgan failure within the first 14 days after the operation. The majority of patients in both groups experienced a complicated postoperative course, and a significant number of postoperative complications were observed (Table 4). The most common postoperative complication in both groups was acute renal failure requiring temporary hemodialysis. The mean stay in the intensive care unit was prolonged in all patients (group A: $5 \pm 3$ days [range, 2-28 days]; group B: $6 \pm 4$ days [range, 3-36 days]; $P>$.2).

Median follow-up was 21 months (range, 1-48 months) for group A and 34 months (range, 1-152 months) for group B $(P>.2)$. No patients were lost to follow-up. During follow-up, no recurrent prosthetic valve endocarditis was diagnosed, and no patient had to undergo reoperation. Survival at 1 and 5 years was $81 \% \pm 10 \%$ and $81 \% \pm 10 \%$ in group $\mathrm{A}$ and $85 \% \pm 10 \%$ and $85 \% \pm 10 \%$ in group B, respectively $(P>.2$, Figure 1$)$.

\section{Discussion}

The results of this study indicate that the material (biologic vs prosthetic) used for aortic root replacement has no effect on hospital mortality, long-term mortality, and the incidence of recurrent PVE in patients requiring redo aortic root surgery for PVE associated with infectious destruction of the aortic root.

The surgical goal in the treatment of PVE combined with infectious destruction of the aortic root is a low rate of recurrent PVE. It has been argued that the use of homograft material as a valve substitute in the setting of PVE with infectious destruction of the aortic root is associated with a lower mortality and a lower incidence of recurrent PVE compared with prosthetic material. ${ }^{9-11}$ We were not able to detect any differences regarding hospital mortality between the groups (group A, 18.7\%; group B, $15.4 \% ; P>.2$ ). The
TABLE 4. Perioperative complications

\begin{tabular}{|c|c|c|c|}
\hline Complication & $\begin{array}{l}\text { Group A } \\
(n=16)\end{array}$ & $\begin{array}{l}\text { Group B } \\
(n=13)\end{array}$ & $P$ value \\
\hline Hospital mortality (n [\%]) & $3(18.7 \%)$ & $2(15.3 \%)$ & $>.2$ \\
\hline $\begin{array}{l}\text { Atrioventricular block } I I^{\circ} \\
\text { (n [\%]) }\end{array}$ & $4(25 \%)$ & $2(15.4 \%)$ & .013 \\
\hline Stroke (n [\%]) & $2(12.4 \%)$ & $1(7.7 \%)$ & $>.2$ \\
\hline Acute renal failure (n [\%]) & $7(43.7 \%)$ & $8(61.5 \%)$ & $>.2$ \\
\hline $\begin{array}{l}\text { Low cardiac output } \\
\text { syndrome (n [\%]) }\end{array}$ & $3(18.7 \%)$ & $4(30.8 \%)$ & $>.2$ \\
\hline $\begin{array}{l}\text { Prolonged artificial } \\
\text { ventilation, }>48 \mathrm{~h} \text { (n } \\
{[\%] \text { ) }}\end{array}$ & $6(37.5 \%)$ & $8(61.5 \%)$ & $>.2$ \\
\hline
\end{tabular}

Note that some patients had more than one postoperative complication.

overall mortality in our study cohort of $18.7 \%$ is comparable with what other investigators have previously reported. In the most recent studies, hospital mortality for PVE varied between $9.4 \%$ and $32 \% .^{2-4,8-10}$ Moreover, a meta-analysis from the United Kingdom heart valve registry showed a similar mortality rate averaging $20 \% .{ }^{18}$ The second important issue in the treatment of PVE beside mortality is the incidence of recurrent PVE. Delay and coworkers ${ }^{19}$ demonstrated that surgical intervention for PVE can be performed with no hospital deaths; however, in this study freedom from reoperation was only $45 \%$ after 1 year.

We speculate that this might be the result of an intraoperative eradication failure of the underlying organism from the aortic root. In our patient population we had no recurrent PVE with a total follow-up of $47 \pm 44$ months (range, 1-152 months). Lytle and associates ${ }^{9}$ showed a recurrent rate of $3.8 \%$ within 1 year after surgical intervention for PVE by using homograft aortic root replacement as the second procedure. Hagl and colleagues ${ }^{10}$ demonstrated, with an almost identical patient cohort, a 4\% recurrence rate for PVE after using prosthetic composite graft replacement for the treatment of PVE. In both series the entire aortic root was replaced either with homografts or prosthetic material. These findings might support the strategy of using aggressive surgical intervention to replace the aortic root in patients presenting with PVE. Data comparing the effect of biologic (homograft-autograft) material or prosthetic material on outcome in patients with PVE and infectious aortic root replacement are rare. Haydock and coworkers, ${ }^{11}$ as well as and McGiffin and associates, ${ }^{12}$ underlined the advantage of homograft aortic root replacement for PVE associated with annular destruction in a comparative study comparing homograft versus prosthetic aortic replacement for PVE. However, none of these studies were randomized, and the number of patients involved was limited. Recent published studies dealing with the problem of PVE and infectious destruction of the aortic root showed excellent 


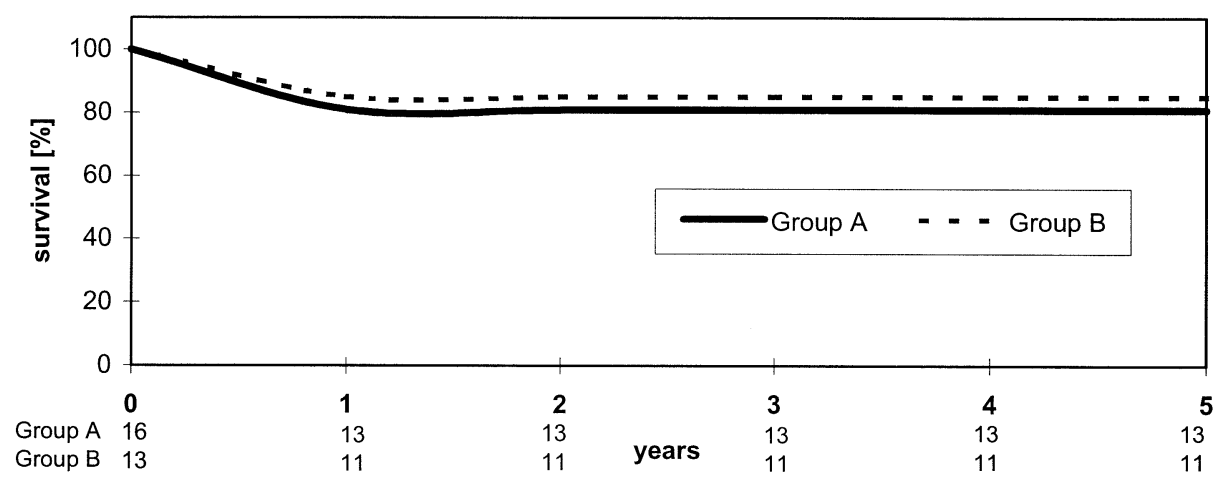

Figure 1. Survival in patients after prosthetic composite (group A) and aortic allograft root (group B) replacement: replacement for acute prosthetic aortic valve endocarditis.

short-term and long-term results: one group used homograft material, and the other group used prosthetic material for aortic root replacement in the presence of PVE. ${ }^{9,10}$ The results from these studies did not differ in terms of shortand long-term survival or in the incidence of recurrent PVE. From these studies and our own results, we believe that other factors in addition to the material used for the treatment of PVE might influence the outcome. Delahaye and associates $^{20}$ showed that undue delay of operation for endocarditis is common and that the delay in surgical treatment might result in more severe infectious destruction of cardiac structures, with all resulting consequences. Furthermore, a more aggressive surgical approach to the treatment of PVE seems to influence the outcome. ${ }^{10,21} \mathrm{Hagl}$ and associates ${ }^{10}$ stressed that patients presenting with PVE combined with infection beyond the valve annulus are best treated with aortic root replacement rather than aortic valve replacement and repair of annular destruction because of decreased hospital mortality after aortic root replacement. In our opinion a radical surgical approach with resection of all infectious and necrotic tissue regardless of the cardiac structures involved followed by complete aortic root replacement might be the clue to success in the treatment for PVE with infectious destruction of the aortic root.

\section{Limitations}

We wish to address several limitations. First, the number of patients in each group is too small to draw definite conclusions concerning the material that should be used in PVE with infectious destruction of the aortic root. However, in the most recent publications, the patient cohort with complicated PVE was almost similar to ours. ${ }^{6,9,10}$ Second, patients were not prospectively randomized, and the selection for either homograft or prosthetic aortic root replacement was dependent on the surgeon's preference only. Furthermore, the severity of the infection and the causative microorganism might vary between different patient cohorts.

\section{Conclusions}

Keeping all the aforementioned drawbacks of this study in mind, we believe that the material used for aortic root replacement in PVE with infectious destruction of the aortic root has no major effect on postoperative outcome. The strategy of early reoperation for PVE, thorough debridement, aggressive surgical technique, and prolonged antibiotic treatment might reduce mortality and the incidence of early and late recurrent PVE and improve long-term survival.

\section{References}

1. Blumberg EA, Karalis DA, Chandrasekaran K, Wahl JM, Vilaro J, Covalesky VA, et al. Endocarditis-associated paravalvular abscesses. Do clinical parameters predict the presence of abscess? Chest. 1995; 107:898-903.

2. Glazier JJ, Verwilghen J, Donaldson M, Ross DN. Treatment of complicated prosthetic aortic valve endocarditis with annular abscess formation by homograft aortic root replacement. J Am Coll Cardiol. 1991;17:1177-82.

3. Watanabe G, Haverich A, Speier R, Dresler C, Borst HG. Surgical treatment of active infective endocarditis with paravalvular involvement. J Thorac Cardiovasc Surg. 1994;107:171-7.

4. Moon MR, Miller DC, Moore KA, Oyer PE, Mitchell RS, Robbins $\mathrm{RC}$, et al. Treatment of endocarditis with valve replacement: the question of tissue versus mechanical prosthesis. Ann Thorac Surg. 2001;71:1164-71.

5. d'Udekem Y, David TE, Feindel CM, Armstrong S, Sun Z. Long-term results of operation for paravalvular abscess. Ann Thorac Surg. 1996; 62:48-53.

6. Dossche KM, Defauw JJ, Ernst SM, Craenen TW, De Jongh BM, de la Riviere AB. Allograft aortic root replacement in prosthetic aortic valve endocarditis: a review of 32 patients. Ann Thorac Surg. 1997; 63:1644-9.

7. David TE. Surgical management of aortic root abscess. J Card Surg. 1997;12(suppl 2):262-6.

8. Bauernschmitt R, Jakob HG, Vahl CF, Lange R, Hagl S. Operation for infective endocarditis: results after implantation of mechanical valves. Ann Thorac Surg. 1998;65:359-64.

9. Lytle BW, Sabik JF, Blackstone EH, Svensson LG, Pettersson GB, Cosgrove DM 3rd. Reoperative cryopreserved root and ascending aorta replacement for acute aortic prosthetic valve endocarditis. Ann Thorac Surg. 2002;74(suppl):S1754-7.

10. Hagl C, Galla JD, Lansman SL, Fink D, Bodian CA, Spielvogel D, et al. Replacing the ascending aorta and aortic valve for acute prosthetic 
valve endocarditis: is using prosthetic material contraindicated? Ann Thorac Surg. 2002;74(suppl):S1781-5.

11. Haydock D, Barratt-Boyes B, Macedo T, Kirklin JW, Blackstone E. Aortic valve replacement for active infectious endocarditis in 108 patients. A comparison of freehand allograft valves with mechanical prostheses and bioprostheses. J Thorac Cardiovasc Surg. 1992;103: $130-9$.

12. McGiffin DC, Galbraith AJ, McLachlan GJ, Stower RE, Wong ML, Stafford EG, et al. Aortic valve infection. Risk factors for death and recurrent endocarditis after aortic valve replacement. $J$ Thorac Cardiovasc Surg. 1992;104:511-20.

13. Lytle BW, Priest BP, Taylor PC, Loop FD, Sapp SK, Stewart RW, et al. Surgical treatment of prosthetic valve endocarditis. J Thorac Cardiovasc Surg. 1996;111:198-207.

14. Niwaya K, Knott-Craig CJ, Santangelo K, Lane MM, Chandrasekaran K, Elkins RC. Advantage of autograft and homograft valve replacement for complex aortic valve endocarditis. Ann Thorac Surg. 1999; 67:1603-8.

15. Sabik JF, Lytle BW, Blackstone EH, Marullo AG, Pettersson GB, Cosgrove DM. Aortic root replacement with cryopreserved allograft for prosthetic valve endocarditis. Ann Thorac Surg. 2002;74:650-9.
16. Petrou M, Wong K, Albertucci M, Brecker SJ, Yacoub MH. Evaluation of unstented aortic homografts for the treatment of prosthetic aortic valve endocarditis. Circulation. 1994;90(suppl):II198-204.

17. Karck M, Siclari F, Wahlig H, Sperling U, Schmid C, Haverich A. Pretreatment of prosthetic valve sewing-ring with the antibiotic/fibrin sealant compound as a prophylactic tool against prosthetic valve endocarditis. Eur J Cardiothorac Surg. 1990;4:142-6.

18. Edwards MB, Ratnatunga CP, Dore CJ, Taylor KM. Thirty-day mortality and long-term survival following surgery for prosthetic endocarditis: a study from the UK heart valve registry. Eur J Cardiothorac Surg. 1998;14:156-64.

19. Delay D, Pellerin M, Carrier M, Marchand R, Auger P, Perrault LP, et al. Immediate and long-term results of valve replacement for native and prosthetic valve endocarditis. Ann Thorac Surg. 2000; 70:1219-23

20. Delahaye F, Rial MO, de Gevigney G, Ecochard R, Delaye J. A critical appraisal of the quality of the management of infective endocarditis. J Am Coll Cardiol. 1999;33:788-93.

21. Pelletier LC, Baillot R, Auger P, Dyrda I. Early valve replacement in active infective endocarditis. Can J Surg. 1984;27:383-6.

\section{Availability of Journal back issues}

As a service to our subscribers, copies of back issues of The Journal of Thoracic and Cardiovascular Surgery for the preceding 5 years are maintained and are available for purchase from Elsevier Inc. until inventory is depleted. Please write to Elsevier Inc., Subscription Customer Service, 6277 Sea Harbor Dr, Orlando, FL 32877, or call $800-654-2452$ or $407-345-4000$ for information on availability of particular issues and prices. 